\section{Harmony among physicists}

SIR-I would like to comment on the article entitled "Is the end of particle proliferation at hand?" (Nature 341, 555; 1989), which gives a distorted and alarming picture about how scientific research proceeds and progresses.

True, the scientific importance of the results announced about the measurements of the $\mathrm{Z}^{0}$-width both at SLAC and at CERN is presented to readers, but at the same time - and quite unnecessarily in my opinion - there is an added element of rivalry and hostility.

Your article also gives a totally distorted view of my own "reactions" to this important result, based solely on some statements I am said to have made to the Italian newspaper La Repubblica. In fact I have never granted such an interview to the author of the article, Arnaldo d'Amico. He has based his "story" on patched up, "secondhand" information from local news agencies which have twisted the meaning of my words on the occasion of a scientific talk in Pisa. This has been fully clarified in a letter to the editor of La Repubblica, published on 20 October. Finally, even in your "translation" from Italian into English, there are some significant exaggerations.

I am surprised that a journal of the scientific reputation of Nature did not verify the authenticity of the story (for instance checking what I said with me directly) before going to press. The article would then have lost much added spice, but at the same time would have gained objectivity.

The article could also use some brushing up when it comes to scientific matters. The statement that LEP, by virtue of its higher beam energy, has produced more $Z^{0}$ s than SLC is simply shocking: the beams of the two machines must have identical energies in order to tune on the $Z^{0}$. I also fail to see what is meant by the statement that "the lack of a clear answer [on the exact number of additional families] has impeded theoretical understanding". Finally, contrary to what is said in the article, the top quark is not the only particle "awaiting discovery" - the tau-neutrino has also so far escaped direct detection.

It is a great pity that the two announcements of excellent results from both machines have been described mainly as an episode of acrimony and rivalry among scientists, whereas in fact I believe that it is their convergence that is the significant and durable fact.

We all know that, nowadays, fundamental research takes place simultaneously at several laboratories in the world, with the common, ultimate aim of arriving at accurate and confirmed results. In this process, competition is certainly healthy and stimulating, but it rests on the implicit understanding that science is thus best served. Advantage should not be taken to provoke "public quarrels", not even by reporters.

CERN,

European Laboratory

for Elementary Particle Physics,

Meyrin, Geneva, Switzerland

- Nature did seek confirmation of Dr Rubbia's reported remarks in advance of publication, but was told by his office at CERN that he was away and inaccessible. - Editor, Nature.

\section{Attention please}

SIR-Stephen Jay Gould seems to be both right and wrong in his defence of the word 'attendee' to describe someone who attends a meeting (Nature 340, 424; 1989). He is no doubt right to say that the Oxford English Dictionary recognizes the use of the word, but he is surely wrong in assuming that such recognition implies formal approval as correct English. In the absence of a formally constituted governing body, it is probably impossible to state that certain constructions are correct or incorrect for all time. All that we can hope for from a dictionary of English is guidance to current usage; beyond that we simply have to aim for a reasonable level of consistency to avoid confusion. Certainly Americans may use 'attendee' to mean one who attends, but to do so is to mix up the object of the verb in the usual form of construction (such as examinee, one who is examined) with the subject (examiner, the one examining). If you insist upon doing so, and can get enough people to accept your usage, then a dictionary will no doubt in time reflect that fact, but the language as a tool for communication will suffer. English is a difficult enough language as it is because of its loose structure, but that is no reason to throw out such guidelines as we do have and confer the status of neologisms on mistakes.

By the way, in the spirit of Gould's reply to David Pyke and if one wishes to assess correctness on the basis of usage, it is simply not true to assert that 'attender' "has never been used to mean 'one who attends a meeting". The Concise Oxford Dictionary of Current English (1982) gives 'attender' as the noun for one who attends in the sense, among others, of "be present at (lecture, etc.)". So where is the linguistic need claimed by Gould?

Department of Human Anatomy

ALAN TURNER

and Cell Biology,

University of Liverpool,

POBox 147 ,

Liverpool L69 3BX, UK
South African aid?

SIR-I hold no special brief for the views expressed by File et al. (Nature 341, 96-98; 1989 ) in their article "Towards the day of hard choices" about education in South Africa, but I believe it behoves all scientists to get out their calculators and do a few sums on the figures they quote.

Table 1 gives the per capita expenditure on white education in 1987 as R2,508 and on black as R477. The number of scholars for the same year is given as 954,000 white and 6,645,000 black. From these numbers, expenditure on education in 1987 can be calculated to be R5.6 $\times 10^{9}$. Education is said to consume "a respectable 20 per cent of public expenditure".

If in 1987 expenditure on black education had been at the same per capita rate as for whites (and I doubt whether the expenditure on white scholars would count as very generous by standards elsewhere in the West), the cost would have been 3.4 times greater at R1.9 $\times 10^{10}$, equal to 68 per cent of public expenditure.

Education, as stated by File et al., is in competition with other much-needed public expenditure, whatever savings might arise from the elimination of apartheid. Direct taxation is not low by international standards and there is a general sales tax of 13 per cent. Government, moreover, is committed to trying to contain public expenditure in order to control inflation.

To spread the 1987 budget evenly raises the expenditure for blacks by 50 per cent to R732, but will barely scratch the surface of the problem of providing an adequate system for all. To bring the 1987 school population to white levels of expenditure over 5 or 10 years would require a real per annum compound growth in the education budget of 28 per cent or 13 per cent respectively - by an economy currently experiencing a growth rate of 1-2 per cent.

File et al. quote projections suggesting that by the year 2020 the school population will be 899,000 whites and 14,977,000 blacks. If they are all to receive education equivalent to that of whites today, the cost at 1987 prices will be $\mathrm{R} 4 \times 10^{10}-$ a sevenfold increase over 1987 and requiring a real per annum compound growth of expenditure of 6 per cent.

I feel confident, if not happy, in predicting that such increases will not be achieved unless there is massive international aid, either to education directly or to boost the economy so that it can itself generate the necessary wealth. The "hard choices" are not really South Africa's - there are too few resources to allow that luxury - but the outside world's: whether to help or not.

Department of Biochemistry,

K. L. MANCHESTER University of the Witwatersrand, Johannesburg, South Africa 